Proceedings

\title{
Microwave Heating Impact on the Oil Yield from Botryococcus braunii Algae Biomass ${ }^{\dagger}$
}

\author{
Magdalena Rokicka ${ }^{1, *}$, Marcin Zieliński ${ }^{1}$, Marcin Dębowski ${ }^{1}$ and Katarzyna Głowacka ${ }^{2}$ \\ 1 Department of Environmental Engineering, University of Warmia and Mazury in Olsztyn, Warszawska St. \\ 117A, 10720 Olsztyn, Poland; marcin.zielinski@uwm.edu.pl (M.Z.); marcin.debowski@uwm.edu.pl (M.D.) \\ 2 Department of Plant Physiology, Genetics and Biotechnology, University of Warmia and Mazury in \\ Olsztyn, Oczapowskiego Str. 1A, 10719 Olsztyn, Poland; katarzyna.glowacka@uwm.edu.pl \\ * Correspondence: magdalena.rokicka@uwm.edu.pl; Tel.: +48-536-832-232 \\ + Presented at Environment, Green Technology and Engineering International Conference (EGTEIC 2018), \\ Caceres, Spain, 18-20 June 2018.
}

Published: 26 October 2018

\begin{abstract}
Stage, which is still difficult for researchers is extraction of the lipids, especially the cell disruption stage prior to the extraction process. Strength of cell walls of microalgae makes lipids difficult to access. The aim of the experiment was to determine the influence of microwave electromagnetic radiation on the efficiency of lipid extraction from Botryococcus braunii microalgae by Bligh \& Dyer method. he use of microwave heating to disintegrate the biomass of microalgae allowed to increase the yield of lipids from 18\% in Stage I to 38\% in Stage II in incubation time of 15 $\min$ in $45^{\circ} \mathrm{C}$.
\end{abstract}

Keywords: microalgae; microwave; lipids

\section{Introduction}

The introduction should briefly place the study in a broad context and define the purpose of the work and its significance.

For papers that report original research, you should use the titles "Materials and Methods", "Results", "Discussion" and "Conclusions" (optional). Oil microalgae has been recognised as the most promising source of renewable oils used in the production of liquid biofuel. Although microalgae offers great potential, it has not been used sufficiently since biodiesel production based on microalgae poses technological problems. Some microalgae species can produce ten times more oil than the typical oil crops [1]. Botryococcus braunii is characterised by an apparent ability to synthesise and accumulate a wide variety of reserve substances with the most promising composition for biofuel production. The accumulation of such an amount of carbohydrates can be achieved by storing lipids in an extracellular space as opposed to the cytoplasm, as is the case in other oil microalgae [2]. However, the analysis of the fatty acid composition showed that carrying out an algae culture at above $30^{\circ} \mathrm{C}$ considerably reduces the content of unsaturated fatty acids contained in them, which is essential in biofuel production. The physiological properties of the majority of microalgae species with such a small cell size (3-20 $\mu \mathrm{m})$ and their low concentration in a culture, result in energy consuming harvesting, separation and drying processes [3]. In order to minimise energy used to dewater algae, much effort has been concentrated on developing biodiesel production technology from wet algae, because drying microalgae after harvest consumes up to $20-30 \%$ of the total cost of biodiesel production [3,4]. Since algal cellular walls exhibit a wide variability in molecular components and intra- and inter molecular bonds, the phase which still poses problems is the lipid extraction phase, including disintegration of the cellular walls before extraction $[5,6]$. To this end, mechanical, chemical and enzymatic methods of cell disintegration are utilised. This results mainly 
from the fact that microwaves can penetrate deeply through cellular wall structures. Fast heating ensures a high internal temperature and the difference in pressure exerted on the cellular walls may accelerate mass transfer without the need for thermal decomposition of lipids. One of the advantages of this method is a more uniform increase in temperature in comparison with the conventional heating methods. For some microalgae, the microwave treatment is considerably more effective than ultrasound or milling beads. Due to its technical simplicity, the other advantages of microwave disintegration include effectiveness, durability and, above all, ease in transferring from the laboratory to the technical scale $[7,8]$.

Since the extraction phase currently constitutes more than $50 \%$ of the total energy consumption, developing effective methods of pre-treatment of microalgae may significantly reduce energy demand and the costs of microalgal biomass production on a large scale $[3,9]$. The aim of the experiment was to determine the influence of microwave electromagnetic radiation on the efficiency of lipid extraction from Botryococcus braunii microalgae by the Bligh \& Dyer method.

\section{Materials and Methods}

Algal biomass of the genus Botryococcus brauni are propagated in 1 litre photobioreactors. Reactors are placed in a climate chamber with favourable temperature conditions $\left(25-28{ }^{\circ} \mathrm{C}\right)$, adequate lighting and humidity. By changing the culture conditions (nitrogen elimination from synthetic medium), microalgae accumulates lipids. A synthetic medium was created by the SAG formula. After obtaining the biomass concentration in the reactor at the level of $2000 \mathrm{mg}$ s.m./l. the algae culture was compacted through sedimentation (Figure 1).

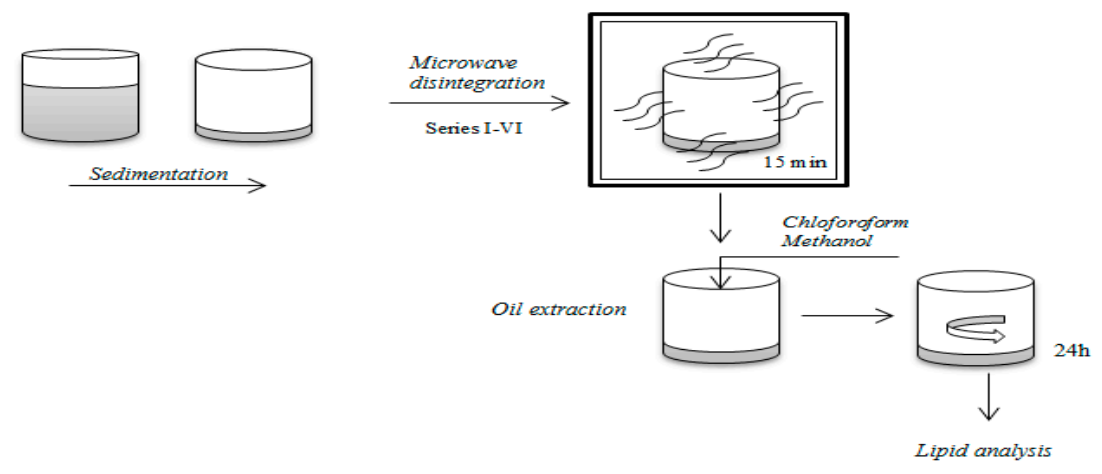

Figure 1. Organization of experiment.

In stage I, the algal biomass after nitric cultivation regime was extracted by the Bligh \& Dyer method. In stage II, the biomass of algae after nitric cultivation regime (before the Bligh \& Dyer extraction method) was pre-treated by microwave disintegration. The dose of microwaves was changed in subsequent series depending on the desired temperature $\left(30-80{ }^{\circ} \mathrm{C}\right)$ with a constant incubation time of $15 \mathrm{~min}$ in each series (Figure 1). Lipids were extracted from the microalgae suspension according to modified Bligh and Dyer method. The fatty acid composition of microalgae depended on the species and culture conditions. For selected indicator samples, an analysis of the cell structure was conducted using a scanning electron microscope. The analysis will focus on the cells before and after disintegration. The samples were dehydrated in a graded series of ethanol concentrations. The suspended material was micro-pipetted on a cover glass and then sputter-coated with gold in an argon atmosphere in an ionic coater. The sputter-coated material was placed in an SEM column (JSM-5310LV, JEOL, Tokyo, Japan) and analysed at 15-30 kV. The FAME analysis of the obtained lipids was performed by gas chromatography using a GC-FID Agilent Technology Analyzer gas chromatograph equipped with a flame-ionization detector. A qualitative analysis identified peaks corresponding to different components of the sample. Ingredients that were identified were compared by their retention times and fragmentation patterns according to standards. The results were processed statistically with the Statistica 10.0 PL package. 


\section{Results and Discussion}

Following a 24-h sedimentation of the multiplied biomass, on day 15 of the experiment, the main part of the experiment was conducted. The concentrated biomass was extracted using the Blight\&Dyer method. The volume of the resulting extract was determined with the gravimetric method. Since the key to extraction effectiveness is an adequate method of cellular structure disintegration, it was found that microwave radiation may have a positive effect on lipid release.

The amount of oil obtained from the control sample was 17.82\% (Table 1). In series I, when the incubation temperature was $30^{\circ} \mathrm{C}$, the amount of oil obtained was $28.71 \%$. A temperature increase of $15{ }^{\circ} \mathrm{C}$ resulted in an increase in lipid yield of up to $37.62 \%$ from a biomass treated with microwaves at the temperature of $45{ }^{\circ} \mathrm{C}$ (Table 1). Another increase in temperature by $15{ }^{\circ} \mathrm{C}$, did not bring the anticipated effect of a higher lipid yield. Series III and IV, when the incubation temperature was 60 ${ }^{\circ} \mathrm{C}$ and $75{ }^{\circ} \mathrm{C}$, respectively, did not reveal statistically significant differences. The lipid yields were comparable and amounted to $22.77 \%$ and $24.26 \%$ (Table 1). The quality of biodiesel is totally influenced by the composition of fatty acids [10]. Unsaturated fatty acids constituted the majority in the fatty acid profile ( $47 \%$ of the defined acids). The fatty acid profile contained mainly palmitic acid (C16:0) and stearic acid (C18:0). Pates et al. suggest that the combined ultrasound and microwave method is a potential technology of lipid extraction from wet biomass. In this way, they obtained a high amount of saturated $(10.39 \pm 0.15 \%)$ and mono-unsaturated fatty acids $(76.55 \pm 0.19 \%)$, which is a characteristic of a high quality biodiesel [10]. On the other hand, Ali and Watson report that the extraction temperature has an effect on lipid productivity and facilitates in separation of higher unsaturated fatty acids [11].

Table 1. Oil yield.

\begin{tabular}{cccccc}
\hline & Control & Series & Series & Series & Series \\
Sample & I & II & III & IV \\
\hline Temperature of incubation $\left[{ }^{\circ} \mathrm{C}\right]$ & 22 & 30 & 45 & 60 & 75 \\
\hline Incubation time [min] & - & \multicolumn{3}{c}{15 min } \\
\hline Obtained oil [g] & 0.36 & 0.58 & 0.76 & 0.46 & 0.49 \\
\hline $\begin{array}{c}\text { Quantity of organic dry biomass used for the } \\
\text { extraction [g o.d.m.] }\end{array}$ & & & 2.02 & & \\
\hline \begin{tabular}{c} 
Percentage of oil in the biomass [\% o.d.m.] \\
\hline
\end{tabular} & 17.82 & 28.71 & 37.62 & 22.77 & 24.26 \\
\hline
\end{tabular}

The impact of microwave pre-treatment of algae cell on surface morphology after extraction is presented in Figure 2. Microwave-treated cells showed deformed structural morphology compared to cells without any treatment where they were practically intact. Microscope analysis of the biomass of the control sample showed that $99.9 \%$ are undamaged cells (Figure 2a). Microwave-treated cells showed punctures in their cell wall which proved the leakage of cell contents from the cells (Figure 2c). Increasing the disintegration temperature resulted in gradual cell wall destruction but did not increase the oil yield in series III and IV.

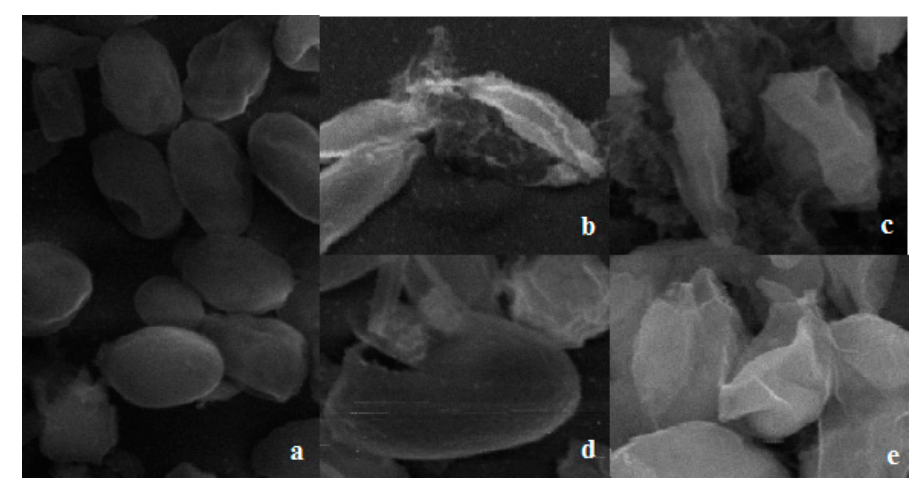

Figure 2. Effects of microwave heating on B. braunii: (a) control sample, (b) series I, (c) series II, (d) series III, (e) series IV. 


\section{Conclusions}

A review of the literature shows that microalgae are a good source of biomass for energy purposes. The use of microwave heating to disintegrate the biomass of microalgae Botryococcus braunii left the cell structures undamaged, which enabled greater amounts of lipids to be achieved. The use of microwave heating to disintegrate the biomass of microalgae increased the yield of lipids from $18 \%$ in Stage I to $38 \%$ in Stage II in an incubation time of $15 \mathrm{~min}$ at $45{ }^{\circ} \mathrm{C}$. Although it is clear that there are benefits to using microwaves to pre-treat microalgae cells prior to lipid extraction, to develop these techniques on a large-scale it is important that more studies are done to optimise the processes.

Author Contributions: M.R. and M.Z. conceived and designed the experiments; M.R. and K.G. performed the experiments; M.D. analyzed the data; M.R., M.Z., M.D. and K.G. wrote the paper.

Acknowledgments: The research was conducted under Project No. 2016/23/N/ST8/03806 from the National Science Centre, Poland and was also supported by Project No. 18.620.023-300 from the University of Warmia and Mazury in Olsztyn.

Conflicts of Interest: The authors declare no conflict of interest. The founding sponsors had no role in the design of the study; in the collection, analyses, or interpretation of data; in the writing of the manuscript, and in the decision to publish the results.

\section{References}

1. Tasić; M.B.; Pinto, L.F.R.; Klein, B.C.; Veljković, V.B.; Maciel Filho, R. Botryococcus braunii for biodiesel production. Renew. Sustain. Energy Rev. 2016, 64, 260-270.

2. Hirose, M.; Mukaida, F.; Okada, S.; Noguchi, T. Active hydrocarbon biosynthesis and accumulation in a green alga, Botryococcus braunii (Race A). Eukaryot. Cell 2013, 12, 1132-1141.

3. Macías-Sánchez, M.D.; Robles-Medina, A.; Jiménez-Callejón, M.J.; Hita-Peña, E.; Estéban-Cerdán, L.; González-Moreno, P.A.; Navarro-López, E. Optimization of Biodiesel Production from Wet Microalgal Biomass by Direct Transesterification Using the Surface Response Methodology. Renew. Energy 2018, doi:10.1016/j.renene.2018.06.001.

4. Mata, T.M.; Martins, A.A.; Caetano, N.S. Microalgae for biodiesel production and other applications: A review, Renew. Sustain. Energy Rev. 2010, 14, 217-232.

5. Lee, S.Y.; Cho, J.M.; Chang, Y.K.; Oh, Y.K. Bioresource Technology Cell disruption and lipid extraction for microalgal biorefineries: A review. Bioresour. Technol. 2017, 244, 1317-1328.

6. Amaro, H.M.; Sousa-Pinto, I.; Malcata, F.X.; Guedes, A.C. Microalgal fatty acids-From harvesting until extraction. Microalgae-Based Biofuels Bioprod. 2017, 369-400, doi:10.1016/B978-0-08-101023-5.00016-9.

7. Lee, J.; Yoo, C.; Jun, S.; Ahn, C.; Oh, H. Comparison of several methods for effective lipid extraction from microalgae. Bioresour. Technol. 2010, 101, 75-77.

8. Balasubramanian, R.K.; Yen Doan, T.T.; Obbard, J.P. Factors affecting cellular lipid extraction from marine microalgae. Chem. Eng. J. 2013, 215-216, 929-936.

9. Kim, T.H.; Suh, W.I.; Yoo, G.; Mishra, S.K.; Farooq, W.; Moon, M.; Shrivastav, A.; Park, M.S.; Yang, J.W. Development of direct conversion method for microalgal biodiesel production using wet biomass of Nannochloropsis salina. Bioresour. Technol. 2015, 191, 438-444.

10. Patel, A.; Arora, N.; Pruthi, V.; Pruthi, P.A. A Novel Rapid Ultrasonication-Microwave Treatment for Total Lipid Extraction from Wet Oleaginous Yeast Biomass for Sustainable Biodiesel Production. Ultrason. Sonochem. 2018, doi:10.1016/j.ultsonch.2018.05.002.

11. Ali, M.; Watson, I.A. Microwave treatment of wet algal paste for enhanced solvent extraction of lipids for biodiesel production. Renew. Energy 2015, 76, 470-477.

(c) 2018 by the authors. Licensee MDPI, Basel, Switzerland. This article is an open access article distributed under the terms and conditions of the Creative Commons Attribution (CC BY) license (http://creativecommons.org/licenses/by/4.0/). 